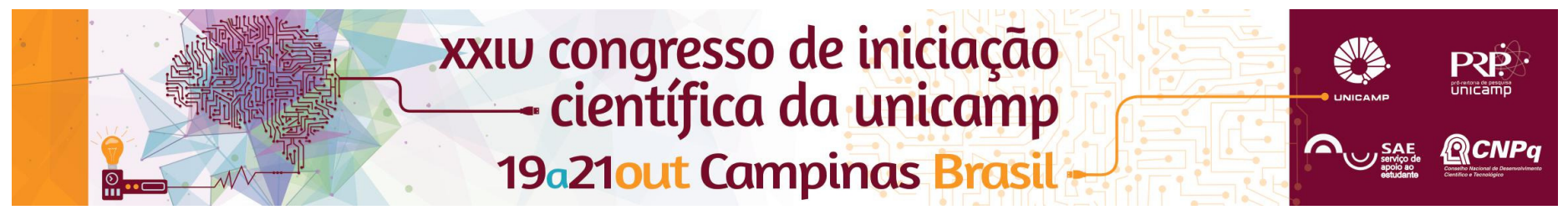

\title{
Análise da adaptação de bases de próteses totais inferiores sobre o efeito de diferentes ciclos de polimerização de resinas acrílicas ativadas termicamente
}

\author{
Raphael de Marco*, Moises C. F. Nogueira, Rafael L. X. Consani
}

\section{Resumo}

O objetivo deste estudo foi avaliar a adaptação de bases de prótese total inferiores sob efeito de ciclos de polimerização em resinas acrílicas ativadas termicamente. Classico (A) 0,1807mm; (B) 0,2465 e (C) 0,2598; Onda Cryl (A) 0,2277; (B) 0,2830 e (C) 0,3110; VIPI, (A) 0,2222; (B) 0,2465 e (C) 0,3006; Vipi Wave, (A) 0,3068; (B) 0,3744 e (C) 0,3495. Não houve diferença estatísticas entre as regiões $\mathrm{A}, \mathrm{B}$ e $\mathrm{C}$ dentre o mesmo grupo, e houve diferenças estatísticas entre as marcas comerciais analisadas.

\section{Palavras-chave \\ Base de prótese, adaptação, resina acrílica, polimerização}

\section{Introdução}

O objetivo deste estudo foi avaliar a adaptação de bases de prótese total inferiores sob efeito de ciclos de polimerização em resinas acrílicas ativadas termicamente. Foram confeccionadas amostras com resina acrílica Clássico (convencional) e Onda Cryl (micro-ondas), e Vipi (convencional) e Vipi Wave (microondas). Foram obtidos 40 conjuntos de gesso-base de cera distribuídos em 4 grupos $(n=10)$ de acordo com a marca comercial e o tipo de polimerização. A proporção pó/líquido e manipulação das resinas acrílicas foram efetuadas de acordo com as recomendações dos fabricantes. As amostras foram incluídas em muflas metálicas e plásticas com gesso pedra e a prensagem das bases feita pelo método convencional. Após polimerização nos ciclos $\mathrm{A}$ - água aquecida a $74^{\circ} \mathrm{C}$ por 9 horas; B- microondas com $1400 \mathrm{~W}$ de potência 20 minutos a $10 \%$ da potência e 5 minutos a $40 \%$ (Vipi Wave); e 3 minutos a $30 \%$ da potência, 4 minutos a $50 \%$ da potência e 3 minutos a $60 \%$ da potência (Onda Cryl), as bases foram demufladas após esfriamento em temperatura ambiente, submetidas ao processo de acabamento e polimento convencionais, e fixadas nos respectivos modelos de gesso com adesivo à base de cianoacrilato. Em seguida foram seccionadas em três porções, correspondentes a distal de caninos $(A)$, mesial de primeiros molares (B) e região palatina posterior (C). Em cada conjunto, o desajuste entre o modelo de gesso e a base de resina foi verificado nos seguintes pontos referenciais: fundo do sulco vestibular direito e esquerdo, crista do rebordo alveolar direita e esquerda e linha mediana palatina. A adaptação foi medida com microscópio comparador linear Olympus, com precisão de $0,0005 \mathrm{~mm}$.

\section{Resultados e Discussão}

Os resultados foram submetidos à análise estatística e as médias comparadas pelo teste Tukey e ANOVA 2 fatores com significância de $5 \%$. Para resina Classico, os valores médios de desajuste foram (A) $0,1807 \mathrm{~mm}$; (B) 0,2465 e (C) 0,2598 . Para resina Onda Cryl, as médias foram (A) 0,2277 ; (B) 0,2830 e (C) 0,3110 ; para a resina VIPI, (A) 0,2222; (B) 0,2465 e (C) 0,3006; e para resinas Vipi Wave, (A) 0,3068; (B) 0,3744 e (C) 0,3495.

\section{Conclusões}

Os ciclos de polimerização influenciaram na adaptação das bases de prova. Não houve diferença estatísticas entre as regiões $A, B$ e $C$ dentre o mesmo grupo, e houve diferenças estatísticas entre as marcas comerciais analisadas.

\section{Agradecimentos}

Os autores agradecem o apoio do $\mathrm{PIBIC/CNPq}$ para desenvolvimento da pesquisa na Faculdade de Odontologia de Piracicaba, da Universidade Estadual de Campinas, SP, Brasil.

Anusavice KJ. Phillips Materiais Dentários. 11. ed., Rio de Janeiro; Elsevier:2005.

Chen JC, Lacefild WR, Casteblerry DJ Effect of denture thickness and curing cycle on the dimensional stability of acrylic resin denture bases. Dent. Mater 1988; 4(1): 20-24.

Consani RLX, Domitti SS, Mesquita MF, Almeida, MHW. Influência de operadores na adaptação das bases de prótese total. Rev Pós-Grad Fac Odontol 2000; 3(1):74-80.

Consani RLX, Domitti SS, Correr Sobrinho L, Sinhoreti MAC. Efeito do tempo pós-prensagem da resina acrílica na alteração dimensional da base de prótese total. Pesqui Odontol Bras 2001; 15(2):112-118.

Consani RLX, Domitti SS, Consani S. Effect of commercial acrylic resins on dimmensional accuracy of the maxillary denture base. Braz Dent J 2002; 13(1):57-60.

Jackson AD, Grisius RJ, Fenster RK, Lang BR. The dimensional accuracy of two denture bases processing methods. Int J Prosthodont 1989; 2 (5): 421-8.

Nishii M. Curing of denture base resins with microwave irridiation: with particular reference to heat-curing resins. J Osaka Dent. Univ. 1968:2(1):23-40.

Padovam SHM, Domitti SS, Consani S. Influência dos ciclos de polimerização sobre a adaptação das bases de prótese total confeccionadas com resina acrílica QC-20. Salusvita 1999; 18(2):73-88

Skinner EW. Acrylic resins: an appraisal of their use in dentistry. J Am Dent Assoc 1949; 39 (3): 261-268

Takamata T, Setcos JC, Phillips RW, Boone ME. Adaptation of acrylic resin dentures as influenced by the activation mode of polymerization. J Am Dent Assoc 1989; 119 (4): 271-6. 